\title{
On Application of MBO in College Management
}

\author{
Xihuai Liu \\ Department of economics and management \\ Zhoukou Normal University, Zhoukou 466001, China \\ E-mail: huaixi06@163.com
}

The research is financed by Social Science Federation of Henan Province. No. skl-2009-1913

\begin{abstract}
MBO (Management by objectives) was firstly put forward by peter F. Drucker (who was a well-known scholar of management in America) in 1954 .MBO was applied in many organizations after a number of management scholars developed and perfected it. $\mathrm{MBO}$ is a comprehensive and democratic systemic management style which is work-centered and people-centered. At first, MBO was widely applied in management of enterprise as a kind of democratic management fashion. This paper organically make some characteristics of MBO and college management together to talk about the feasibility and importance of MBO in college management, as well as several questions should be noticed and tasks of leaders about MBO in college management.
\end{abstract}

Keywords: Application, College management, Feasibility, Importance, MBO

\section{Introduction}

MBO (Management by objectives) was firstly put forward by peter F. Drucker(who was a well-known scholar of management in America ) in 1954 .MBO was applied in many organizations after a number of management scholars developed and perfected it. $\mathrm{MBO}$ is a comprehensive and democratic systemic management style which is work-centered and people-centered. $\mathrm{MBO}$ is a suit of systematization democratic management style which Higher-level and lower-level managers and employees in a organization together set down the common organization goal, form one goal system and specify and outspread to every department, every administrative level, every employee in organization and ties nearly up with their duty and production of every department, every administrative level, every employee within organization, definitely prescribe their consecration and encouragement .

$\mathrm{MBO}$ is different from traditional goal. conventional goals are made by the top management then decompose them into all levels of organization, which is one kind of unilateralism process superior make give goals to junior .such goals are non-operational because junior just passively accept goals .supervisors of all levels explain these goals with a lot of understanding of their own even with prejudice because of the lack of communication. As a result, goals will lose those clarity and consistency during the process of decomposition from above to below, even passive embracer of goals often complain .They consider goals are non-reasonable, their work enthusiasm decline and so on,which directly result in lacking power of implementation. The core of MBO is made goals by top and lower levels of organization together and form goals system, so that the specific objectives of the organization become action direction and motivation of each member, each level, each department, at the same time these goals become standards which check work performance of each member, each level,each department, thus the organization can effectively run. MBO emphasizes self-directing, self-control, not by his superiors to command and control.

In general, Institutions of higher learning are places which intellectual employees are dense. So-called intellectual employees mean them have their own strong power of learning knowledge and innovating knowledge and innovate, spread, share, use knowledge in the organization and create greater value for the organization. How to motivate knowledge workers, in recent years, many scholars from home and abroad carry through theory exploring and demonstration analysis from incentive factors and so on. However, existing studies are often concerned about infection intension of all kinds of incentive factors namely environmental force on action individual 1-- incentive external force .However, self -motivation about action individual --- incentive internal force is not attracted sufficient attention. Could MBO apply in universities management to effectively motive these knowledge-based employees? In previous studies, the author has studied the feasibility of MBO in colleges management, So, This paper organically make some characteristics of MBO and college management together to talk about the problems should be paid attention to during the process of implementation of MBO, and 
specific mission of leaders, as well as the implementation .

\section{Questions should be paid attention to MBO in college management}

\subsection{Questions should be paid attention to when design the overall goal}

The designing overall goal should have challenge and feasibility. The overall goal is the wanted attaining state or result during a certain stage of common aspiration, purpose and mission of the college. to determine overall goal is under the condition of how to estimate its own resources and external environment conditions to design one common aspiration which is related with fact to act as the specific direction and established responsibilities which all the members of organization will do in a period of time in the future. Emancipate the mind and seeking truth from facts, combine the needs of the society with its own conditions, lucubrate and predict the future to design goals. We should properly handle the relationship between goals and conditions, because conditions affect the goals level, the goal can promote the conditions to develop, the two are interlinked and inseparable. Thus, according to the requirements of goals and the "necessary and sufficient" principle, it is very important to establish the condition system to ensure to realize the goals. When the objectives and requirements may be much higher than the protection conditions, the target must is blind, there is no possibility to realize. Conversely, if conditions are too full, the target is conservative, which would result in wastage. Only they are basically the same, can we achieve that objectives have challenge and feasibility.

All members design the goals, rather than traditional top-down to design the goals. MBO itself is the senior management personnel, lower management personnel, as well as all the employees of an organization to design the goals of the organization to form one goal system . MBO is different from traditional goal. conventional goals are made by the top management then decompose them into all levels of organization, which is one kind of unilateralism process superior make give goals to junior .such goals are non-operational because junior just passively accept goals. Supervisors of all levels explain these goals with a lot of understanding of their own even with prejudice because of the lack of communication. As a result, goals will lose those clarity and consistency during the process of decomposition from above to below,even passive embracer of goals often complain .They consider goals are non-reasonable,their work enthusiasm decline and so on,which directly result in lacking power of implementation. The core of MBO is made goals by top and lower levels of organization together and form goals system, so that the specific objectives of the organization become action direction and motivation of each member, each level,each department, at the same time these goals become standards which check work performance of each member, each level,each department, thus the organization can effectively run.

\subsection{Problems should be should be noted when the overall goal outspread}

Outspread the overall goal according to she department and level until to every faculty. This outspreaded process is the so-called top-down process, but this process is only the superior give subordinate one initial recommendation goal, rather than the final decision target. However, this top-down work is very important, if it is not so,the determinate overall objective may not achieve .each level, every department, every member of the school can finally bring forward their own goals according to their own positions and responsibilities as well as the primary goals which the superior give subordinate. They must report the goals to the leaders after bring forward their own goal this is so-called down-top process.

School Leaders should compare the bottom-up goals with the top-down goals, analyze their differences, consult subordinate views and ideas, then revised the goals and then give them to subordinate. the subordinate still modify the goals and then report them to leaders. After such up and down repeatedly modify, ultimately the overall goal would be decomposed into a target system, and issued to corresponding level, departments and every faculty. When the goals are made to the each level,departments and every faculty .specific instructions, specific requirements,independent authority as well as corresponding motivation also should be made known to lower levels,so as to each level, department and every faculty may know their specific work direction,burden and the behavior motivation .

\subsection{Problems should be noted during the process of implementation of $M B O$}

Leaders should hold the direction of the overall goal during the process of implementation of MBO .Once the goals are established, the goals will be the gist which organize and correspond all the management activities .Organizational goals determine the direction of every work in a organization, determine the basic task and expected outcomes of every department, restrict the actions of all employees. Therefore, we must ensure that the target direction is right. If the target direction is wrong, the effort is more great, management performance will be more worse. Leaders must grasp the direction of the goal, Firstly, clearly know the request of superiors, so that the objectives of their own department become the effective step which realize higher-level objectives. 
Secondly, make goals reflect basic mission of their own department. Thirdly, establish the phase goals under the premise of long-term strategic objectives identified, should not go one step further and look forward, or rely on the command of higher level to work.

Appropriately control during the process of implementation of $\mathrm{MBO}$.Control is an important function of management, namely check and weigh implementation of the plan according to the predetermined plan and standard measure, and adjust the action or the plan according to the deviation, so as to everything is known fairly well, everything in the hands, thus to achieve organizational goals better. Moderate control is that the scope, degree and frequency of the control is neither more nor less than to prevent the control is more excessive or inadequate. If the control is more excessive, it can not reflect characteristics of self-control in MBO, thus snuff out the enthusiasm, initiative and creativity of faculty. If the control is more inadequate, the whole school will be in a state of disunity, which is not conducive to achieve the goals of organization.

Problems should be noted when evaluate the goals. The core of MBO is to make the specific objectives of the organization to become the direction and encouragement of the acts of each member, each level, each department of the organization, at the same time, making them become the standards which evaluate the job performance of each member, each level, each department of the organization, so that make the organization to function effectively. MBO itself is a good way of appraisal method. When apply MBO in colleges and universities which intellectual employees are dense, especially check the faculty, rewards and punishment and realization degree of the goals should be band together organically, besides, pay attention to fairness of the rewards and punishment .when identify the target system in MBO, set down the goals for the leaders at all levels, every department, every faculty and identify their respective responsibilities, which are the standards of evaluation and rewards and punishment, therefore, rewards and punishments should band together organically with the realization degree of goals .In addition, pay attention to fairness of rewards and punishment. Or else,they will lose their enthusiasm, initiative and creativity.

\section{Leaders mission about $\mathrm{MBO}$ in colleges and universities}

\subsection{Grasp the direction of goals}

Goal is the desired results which one organization will achieve in a certain period of time in the future through efforts. Objective just as is the navigation mark and power which we move forward, with which we have the direction for struggle .we must ensure that the direction of the goal is correct during the process of struggling goal. If the target direction is wrong, then the greater the effort is, the greater will be away from the goal. Therefore, The leaders at all levels should grasp the direction of the goal when apply MBO in college management to make the goal of their department accord with the predetermined target system.

\subsection{Carry out the responsibility of the goals}

Only decompose the goals into every post, every individual, can ensure to realize the overall goal. therefore, leaders at all levels should not only strive to do their jobs,but also shoulder some responsibilities of the goals .On the one hand Leaders should pay attention to "ability should be accordant with post", namely use the person according to his ability, the diathesis of the person used should be commensurate with his post in the organization. If Post is high and ability is low, it is difficult to realize the goals ; If post is low and ability is high, then cause the waste of talent. On the other hand to "rights should be commensurate with responsibility", according to the size of responsibility of each person, give the appropriate rights to correspond rights with responsibilities, which is propitious to achieve the overall goal.

\subsection{Mobilize the enthusiasm, initiative and creativity of subordinates}

To fully mobilize the enthusiasm, initiative, creativity of subordinates is the radical way which improves the performance of management . The responsibility of a leader lies in how to use people how to take effective measures to develop, cultivate, enhance the ability of subordinates. During the process of implementation of $\mathrm{MBO}$, if people's competence, ability can not exert fully, it is difficult to achieve the goals of the leaders.

\subsection{Do well the job of harmony, control}

MBO emphasize self-management and self-control, but the leaders should not give up the responsibilities of inspection, guidance. Leaders have to go to investigate and research to predominate the implementation of goals, to discover the problems, or to remind subordinate to correct themselves, or directly intervene and take corrective measures. Leaders also harmonize the connection between the departments or individuals, so that the goals of the every department can develop with equilibrium. 


\subsection{Deal with exceptional problems}

So -called exceptional problems are those problems which are accident, novelty, and the nature and structure are non-specific, and have the significant influence. In order to make better use of MBO in college management and successfully achieve the predetermined target system, leaders at all levels should deal well with the disadvantage influence which is exceptional problems cause.

\section{Implementation of MBO}

This paper mainly takes scientific research of faculty in colleges and universities as the example to introduce the method of MBO in college management. The level of scientific research is one of important indexes which weigh the level of running a school for one college or university, is the core competition power of one college, is one important index which connect with status of one college in all the colleges . Then, how to implement MBO in college taking scientific research as the example?

\subsection{Establish the goals}

Firstly, establish the goals according to the different teachers who their title of technical post is different. In general, the workload of scientific research in one academic year denote one teacher's goal of scientific research. For example, Tab1 denote the different teacher's workload of scientific research in one in one academic year of one certain college, and Tab2 denote the indexes system and standard.

\section{2 specific implementation and management of $M B O$}

During the process of MBO, every teaching department and all teachers should self-consciously complete the workload. At the same time, school management department should carry out appropriate management and supervision. Management department of science research should check each teacher's workload at the end of academic year. If exceed the workload, then give appropriate reward which is predetermined, otherwise, give the appropriate punishment.

\section{Conclusion}

MBO was initially applied in the operation and management of enterprises, Chinese enterprises introduced the method of MBO in the 1980s, and have achieved good results. However, MBO in the management of colleges and universities has not been attached importance to. Can use MBO to mobilize everybody's enthusiasm, initiative and creativity for knowledge-intensive colleges and universities? According to analysis and discussion above, the authors think that: MBO in the management of colleges and universities is totally feasible. But MBO has its merits and shortcomings as a sort of democratic management means, some problems should be paid attention to during the process of application of MBO .In addition, in order to apply well this democratic management of MBO and improve well management level of colleges and universities, leaders should be grasp their own tasks during the idiographic implementation of MBO..

\section{References}

Patrick. J. Montana \& Bruce. (2004). H. Vladimir Richard. Management, Shanghai: Shanghai People's Publishing House.

Stephen. P. Robbins. (1997). Organizational behavior, Beijing: China People's University Press.

Mingjie Rui. (2005). Management - a modern point of view, Shanghai: Shanghai People's Publishing House.

Sanduo Zhou \& Chuanming, Chen. (2005). Management - Principles and Methods, Shanghai: Fudan University Press.

Guo-Hua Xu, De Zhang \& Ping Zhao. (1998). Management, Beijing: Tsinghua University Press.

Xihuai Liu. (2009). Study on feasibility of MBO in college management. International education studies, May,162-164.

Table1. Workload of scientific research for different teachers in one academic year

\begin{tabular}{|c|c|}
\hline The title of technical post & Workload (marks) \\
\hline Tutor & 30 \\
\hline Instructor & 60 \\
\hline Associate professor & 120 \\
\hline Professor & 180 \\
\hline
\end{tabular}


Table2. Standard of indexes

\begin{tabular}{|c|c|c|}
\hline $\begin{array}{l}\text { First rank } \\
\text { index }\end{array}$ & Second rank index & Standard of indexes: (marks) \\
\hline \multirow{6}{*}{$\begin{array}{l}\text { Bookmaking } \\
\text { and Paper }\end{array}$} & Monograph & 400/Book \\
\hline & Compilation & 200/ Book \\
\hline & Translation & 200/Book \\
\hline & Three index & $\begin{array}{l}\text { Nature,Science,600/Book; SCI,EI,ISTP:300/ } \\
\text { Book; And so on }\end{array}$ \\
\hline & Authority, Core periodical paper & Authority $: 120 /$ Book, Generic core $: 60 /$ Book \\
\hline & Generic periodical paper & 30/ Book \\
\hline \multirow{3}{*}{$\begin{array}{ll}\text { Item } & \text { of } \\
\text { scientific } & \\
\text { research } & \end{array}$} & Country rank item & $600 /$ Item \\
\hline & Province and ministry rank item & $300 /$ Item \\
\hline & City rank item & $100 /$ Item \\
\hline \multirow{5}{*}{$\begin{array}{l}\text { Award and } \\
\text { Patent }\end{array}$} & Country rank award & $\begin{array}{l}\text { First rank award:200,Second rank award: } \\
100 \text {,And so on }\end{array}$ \\
\hline & Province and ministry award & $\begin{array}{l}\text { First rank award:100/item,Second rank award: } \\
60 / \text { item,And so }\end{array}$ \\
\hline & Award else & 30/item \\
\hline & Important patent & $500 /$ Item \\
\hline & Generic patent & $300 /$ Item \\
\hline
\end{tabular}

